\title{
Evolution of syncarpy in angiosperms: theoretical and phylogenetic analyses of the effects of carpel fusion on offspring quantity and quality
}

\author{
W. S. ARMBRUSTER ${ }^{\star} \dagger$, E. M. DEBEVEC* \& M. F. WILLSON* \\ *Institute of Arctic Biology, University of Alaska, Fairbanks, AK, USA \\ $\dagger$ Department of Botany, Norwegian University of Science and Technology, Trondheim, Norway \\ \$Terrace Place, Juneau, AK, USA
}

\section{Keywords:}

evolution;

flowering plants;

phylogeny;

pollen competition;

pollination;

syncarpy.

\begin{abstract}
The repeated evolution of fused carpels (syncarpy) is one of the dominant features of angiosperm macroevolution. We present results of new phylogenetic and theoretical analyses to assess the frequency and nature of transitions to syncarpy, and the possible advantages of syncarpy over apocarpy under a variety of ecological conditions. Using a recent molecular estimate of angiosperm phylogeny, we ascertained that a minimum of 17 independent evolutionary transitions from apocarpy to syncarpy have occurred; about three-quarters of these transitions allowed pollen tubes to cross between carpels and fertilize ovules that would otherwise be left unfertilized. Most of these transitions also intensified competition between pollen, potentially enhancing offspring fitness. The high proportion of evolutionary transitions promoting pollen competition and pollen-tube access to all carpels supports the hypothesis that the main advantage of syncarpy is in increasing offspring quality and quantity. The potential advantages of syncarpy were more thoroughly evaluated by analytical and simulation studies. These showed that the advantage of syncarpy over apocarpy involving increased offspringquantity held under conditions of marginal pollination and declined with increasing pollination. The offspring-quality advantage persisted over a wider range of conditions, including under quite high pollination rates.
\end{abstract}

\section{Introduction}

The evolution of syncarpy, the fusion of carpels into a unified compound gynoecium, is considered a key innovation (Endress, 2001) and a repeated and dominant feature of angiosperm evolution (Stebbins, 1974). Whereas most basal angiosperm species have separate carpels (apocarpous), some $83 \%$ of extant species are syncarpous (Endress, 1982). This observation, in combination with systematic relationships among syncarpous and apocarpous taxa, has led to the conclusion that syncarpy has evolved repeatedly in the angiosperms and must be highly adaptive.

Correspondence: W. Scott Armbruster, Department of Botany, Norwegian University of Science and Technology, N-7491 Trondheim, Norway. Tel.: (47) 7359 0339; fax: (47) 7359 6100;

e-mail: Scott.Armbruster@chembio.ntnu.no
Several possible advantages of syncarpy have been proposed. Stebbins (1974) stressed the structural advantage of syncarpy. Defence of developing seeds from seed predators could be enhanced by the fusion of carpels and deployment of structural defence on outer walls of the compound pistil. For a given investment into structural or chemical defence, protection of just one outer wall per carpel (rather than three or four) allows the wall to be thicker and better defended. A second advantage, suggested by Endress (1982), is that syncarpy may evolve in connection with adaptations for dispersal of fruits or seeds. A similar argument can be made for the evolution of syncarpy in response to selection for improving precision of pollen placement on, and pickup from, pollinators. The style of a fused pistil will contact pollinators in a more predictable location than a cluster of separate styles (Armbruster et al., 1999; K. E. Schwaegerle, pers. comm.). 
Two, more subtle, but perhaps more significant, possible advantages of syncarpy relate to the quantity and quality of seeds produced by syncarpous vs. apocarpous (free) pistils. Carr \& Carr (1961) noted that seed production may be compromised by the fact that, in an apocarpous flowers, pollen usually arrives unequally on the multiple stigmas. For example, in an apocarpous flower with two carpels, one stigma may have an excess of pollen (allowing full seed set in one carpel) whereas the second lacks pollen altogether (no seeds set in the other carpel). If this happens in a syncarpous flower (e.g. fully fused, bilocular ovary with incomplete septum, but with free styles and stigmas), the 'excess' pollen may be able to cross to the other carpels and fertilize additional ovules, thereby increasing total seed production. This will generally occur if there is a joint pollen-tube transmission tissue shared by the carpels (the 'compitum'; Carr \& Carr, 1961), allowing pollen tubes to cross between carpels (Carr \& Carr, 1961; Walker, 1978; Endress, 1982; Williams et al., 1993; van der Schoot et al., 1995). This condition is thought to be the rule in flowers with fully syncarpous ovaries that are unilocular or incompletely multilocular, but occurs also in many flowers with multilocular ovaries and post-genital (after initial formation) fusion of styles or stigmas, forming a compitum (Carr \& Carr, 1961; Endress, 1982; Endress et al., 1983).

The ability of pollen tubes to cross between carpels may lead to another possible advantage of syncarpy and functional compita. The condition may increase the intensity of pollen competition (Endress, 1982), which may, in turn, increase the quality of seed produced (Mulcahy \& Mulcahy, 1975, 1987; Mulcahy, 1979; Ottaviano et al., 1980; McKenna \& Mulcahy, 1983; McKenna, 1985; Windsor et al., 1987), and thus be favoured by selection (Mulcahy, 1983; Willson, 1991). Endress (1982) illustrated this advantage clearly with a simple example. Consider two flowers, one apocarpous and one syncarpous, each with four carpels. Assume each carpel has one ovule, and each flower receives 40 pollen grains arriving simultaneously and distributed evenly over the four stigmas (carpels). Under pollen competition, the apocarpous flower will have seeds sired by pollen producing in the fastest tubes (assumed to be the best fathers) of each of four groups of 10 pollen grains. In contrast, the syncarpous flower will have seeds sired by the four best fathers of the entire group of 40. Mean offspring fitness (quality) would be enhanced by the more intense pollen competition experienced in the syncarpous flower. Although ovarian compita (strict or functional) may promote pollen competition, stigmatic compita and extragynoecial compita involving stigmas or terminal portions of styles (Endress et al., 1983), cannot.

Although Carr \& Carr (1961) and Endress (1982) have formulated cogent verbal models of how syncarpy might increase offspring quantity and quality, many issues remain unresolved. For example, how does variation in pollen number and pollen-arrival schedule influence the advantages of syncarpy over apocarpy, and what is the relative importance of seed quantity vs. seed quantity under these conditions? How does pollen arriving on stigmas unevenly (rather than evenly as in the above verbal model) influence the advantages of syncarpy and the relative contributions of offspring quantity vs. quality? How do the advantages of syncarpy change as ovule number, carpel number and pollen number vary across realistic ranges? How does a pollen-germination threshold (the minimum number of grains that must be present for any pollen to germinate) affect the advantages of syncarpy with respect to quantity and quality of seeds (see Snow, 1982; Falque et al., 1995; Mitchell, 1997)? Do these variables operate additively or interactively in the statistical sense?

Endress (1982) also pointed out that some apocarpous flowers possess 'extragynoecial compita.' Under this condition pollen tubes can travel a functional (extragynoecial) compitum to cross between separate carpels, usually through secretions joining appressed or ajacent ovaries or stigmas (Walker, 1978; Endress, 1982; Endress et al., 1983; Williams et al., 1993; Renner et al., 1997). The apparently repeated evolution of extragynoecial compita (Endress, 1982; Endress et al., 1983) suggests the evolutionary importance of enhanced seed quantity and/or quality afforded by pollen tubes crossing between carpels.

The goals of this study were to (1) reassess at a macroevolutionary scale how often various forms of syncarpy and compita have originated independently, using multilocus molecular-phylogenetic data, and (2) explore the microevolutionary dynamics of syncarpy in greater detail than is possible with verbal models, by examining mathematically the possible advantages of syncarpy over apocarpy with respect to offspring quantity and quality. We constructed both detailed analytical and computer-simulation models to address the second goal. Our models allowed pollen to compete in their access to ovules in apocarpous and syncarpous flowers under several conditions: various numbers of pollen grains arriving on stigmas, various numbers of carpels per flower, various numbers of ovules per carpel, and various levels of the pollen-germination thresholds. We examined the additive and interactive effects of this variation on the relative advantages of syncarpy over apocarpy with respect to both quantity and quality of offspring.

\section{Methods}

\section{Phylogenetic analysis}

We used the estimated phylogeny of angiosperm taxa published by Soltis et al. (1999, 2000; P. S. Soltis, pers. comm.), to estimate the number of origins of various forms of syncarpy (strict and functional). This tree is the result of analysis of combined data from three more-or-less independent loci and hence represents a robust molecular phylogeny for the angiosperms. It is a significant improve- 
ment over the Chase et al. (1993) one-gene tree, which has been employed widely for similar purposes (see Silvertown et al., 1997). We used MacClade 3.01 (Maddison $\&$ Maddison, 1992) to map syncarpy and apocarpy onto the estimated phylogeny and thereby estimate the minimum number of origins. We made no assumptions about rates of transformation (i.e. neither ACCTRAN nor DELTRAN options were used, and ambiguous regions show up as 'equivocal') nor about order of character states. All characters were assumed to be reversible. Soft polytomies were left unresolved, but the effect of the uncertainty on the number of origins of syncarpy, compita, etc. was explored by manual rearrangement into dichotomies (Donoghue \& Ackerly, 1996).

Information on the nature and degree of carpel fusion was drawn from Cronquist (1981), Endress (1982, 1995), Endress et al. (1983), Williams et al. (1993), Igersheim \& Endress (1997), Svoma (1998), and Endress \& Igersheim (2000). We wished to distinguish between apocarpy, complete syncarpy, and partial syncarpy and, when the last condition, among the various sites of partial carpel fusion. We used information in the literature to distinguish among the following categories: apocarpous (A), ovaries fused without evident compitum (Sl), ovaries fused with an apparent compitum as indicated by a common pollen-tube-transmission tissue or septal pore (S2), both ovaries and styles fused but stigmas free (S3) ovaries, styles, and stigmas fused (S4), only stigmas fused (S5), stigmas and ovaries fused, latter without a compitum (S6; if ovaries with compitum, then included in S2), and only style fused (S7). A compitum was assumed present under conditions S2-S7. We did not distinguish, however, between fusion that occurs simultaneously with carpel development (congenital fusion) and fusion that occurs after carpel development ('post-genital fusion'; see Endress et al., 1983), because this difference, although developmentally and evolutionarily significant, does not, per se, affect pollen-tube access to the carpels. We also distinguished among forms of extragynoecial compita, in which pollen tubes can cross between carpels, although they are otherwise free. We classified taxa by the site of the potential tube crossover: e.g. at the ovary (E2), at the stigma (E5), and at the style (E7), following the same numbering system as for true syncarpy. Polymorphic groups were broken into two homogeneous subgroups when possible, otherwise treated as polymorphic.

\section{Analysis of offspring quantity and quality}

To examine possible advantages of syncarpy with a basal compitum (S2-S4, S7, above) over apocarpy and noncompital syncarpy (A, S1), we defined a general pollination system with four adjustable parameters: (1) number of carpels per flower (in a realistic range: 5-10; Cronquist, 1981), (2) number of ovules per carpel (in a realistic range: 1-100; Cronquist, 1981), (3) total number of pollen grains to be applied to the flower (also in a realistic range:
1-150 grains per flower; e.g. Armbruster et al., 1995), and (4) pollen-germination threshold (the threshold number below which no pollen germinates) for each stigma [in a reasonable range: 1 (none) - 10 grains per stigma; see Snow, 1982; Mulcahy et al., 1983; Falque et al., 1995; Mitchell, 1997]. It seemed important to assess the effect of pollen-germination thresholds, because, although little studied, these thresholds seem to be common and could have important consequences on the relative advantage of syncarpy. If the number of grains on a stigma met or exceeded the threshold, then all grains on that stigma could participate in competition for fertilization.

We allowed competition to occur among pollen grains by assigning a random number to each grain, denoting fitness or competitive advantage such that competition between two grains results in fertilization by the grain with the higher fitness value. Pollen grains were distributed randomly among available stigmas. With these mechanisms in place, we determined two measures of maternal reproductive success over a range of system parameters for syncarpous and apocarpous flowers: (1) mean seed set (SS) and (2) mean offspring fitness determined by the mean fitness of the pollen that fertilized ovules (pollen-determined fitness: PF) (see Mulcahy \& Mulcahy, 1987). The latter metric (PF) is relevant to both offspring and maternal fitness under the assumption that the genetic quality of offspring for a given maternal genotype varies in response to the genetic quality of the fertilizing pollen grains (Mulcahy $\&$ Mulcahy, 1987; Willson, 1991). In the absence of pollen limitation on seed set, maternal fitness varies with the seed quality. Because total maternal reproductive fitness involves both quantity and quality of seeds set, we produced an overall measure of syncarpy advantage or disadvantage by combining measures for both pollination strategies into a single metric.

$$
\text { Total Fitness Ratio }=\frac{S S_{\text {syncarpy }} \cdot P F_{\text {syncarpy }}}{S S_{\text {apocarpy }} \cdot P F_{\text {apocarpy }}}
$$

With this metric, a value greater than 1 indicates an advantage of syncarpy, whereas a value less than 1 indicates an advantage of apocarpy.

We used an analytical approach to calculate the exact mean $\boldsymbol{S S}$ and $\boldsymbol{P F}$ for smaller numbers of pollen grains, but had to turn to a simulation approach to handle larger numbers. For both approaches, we arbitrarily defined pollen fitness as having a normal distribution with a mean of 100 and a standard deviation of 10 (coefficient of variation $=0.1$ ). Using the analytical approach, we calculated mean $\boldsymbol{S S}$ and $\boldsymbol{P F}$ for five carpels per flower and all combinations of 1-10 ovules per carpel, 1-97 pollen grains and pollen-germination thresholds of 1, 2, 5 and 10. Using the simulation approach, we were able to expand the analysis to all combinations of 5 and 10 carpels per flower, 1,10 and 100 ovules per carpel, 1-20, 25, 30, 35, 40, 50, 60, $70,80,90,100,125$ and 150 pollen grains, and pollengermination thresholds at 1, 2, 5 and 10 . We repeated all 
simulations 5000 times and calculated the average seed set and offspring fitness. We also examined the effect of increasing the variability in pollen fitness using the analytical approach with pollen-fitness coefficients of variation of $0.25(\mu=100, \sigma=25)$ and $0.5(\mu=100$, $\sigma=50$ ) with five carpels per flower, one ovule per carpel, 1-50 pollen grains and a pollen-germination threshold of 1. Analytical analyses were run using S-Plus (Mathsoft Inc., 1994) and simulation analyses were run in GAUSS (Aptech Systems, 1993). A detailed description of analytical calculations is provided in Appendix 1 .

\section{Results}

\section{Phylogenetic analysis of syncarpy}

The available phylogenetic information supports unequivocally the hypothesis of multiple origins of syncarpy from apocarpy (Figs 1-3). The reconstruction of character evolution using parsimony led to the estimate of four to six independent origins of fused ovaries without evident compita and 13-20 independent origins of some form of carpel fusion that provides pollen tubes the opportunity to cross between carpels. Thus there were more than three times as many origins of fusion allowing pollen tubes to cross between carpels as origins not allowing pollen-tubes to cross. This difference is likely to be even greater because compita (e.g. septal pores) are often overlooked (or not reported) in species with polylocular ovaries. In addition, there were another five to six independent origins of extragynoecial compita, also allowing pollen tubes to cross between carpels. There were only two detected reversals from syncarpy to apocarpy (Fig. 2).

Of the fusions allowing pollen tubes to cross between carpels, only two involved fusion of terminal regions

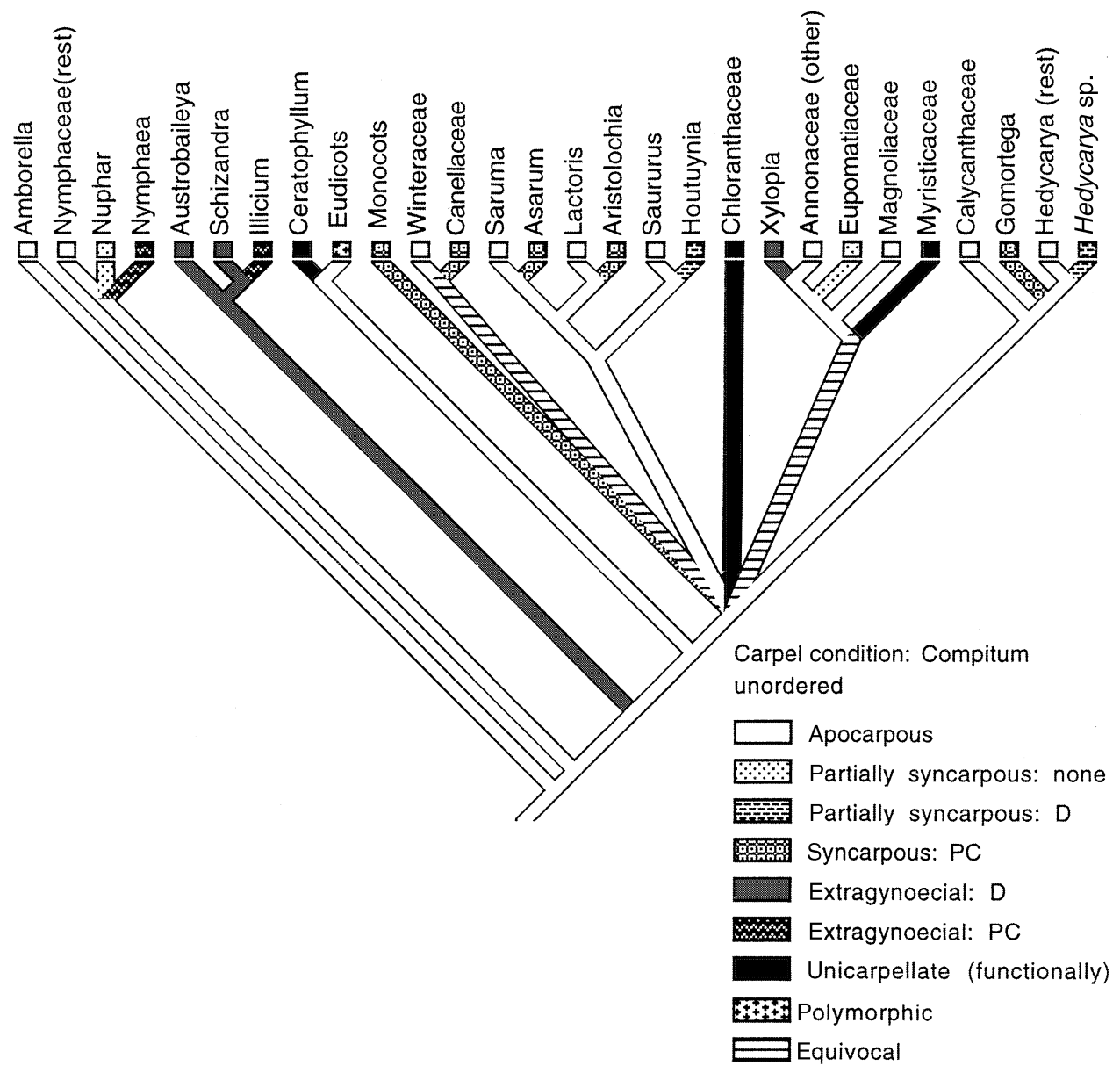

Fig. 1 Estimated phylogeny of basal angiosperms, from Soltis et al. $(1999,2000)$, depicting origins of different forms of syncarpy. Only taxa with informative phylogenetic positions and for which data could be obtained are shown. Abbreviations: D, compitum allowing distributed pollen tubes (syncarpy or extragynoecial compita allowing pollen to fertilize ovules in different carpels); PC, compitum allowing pollen competition (syncarpy or extragynoecial compita allowing pollen competition to occur in addition to fertilization of ovules in different carpels). 'None' refers to absence of compitum. 'Functionally unicarpellate' refers to flowers that are unicarpellate or are pseudomonomerous, regardless of whether they are of apocarpous or syncarpous origin. 


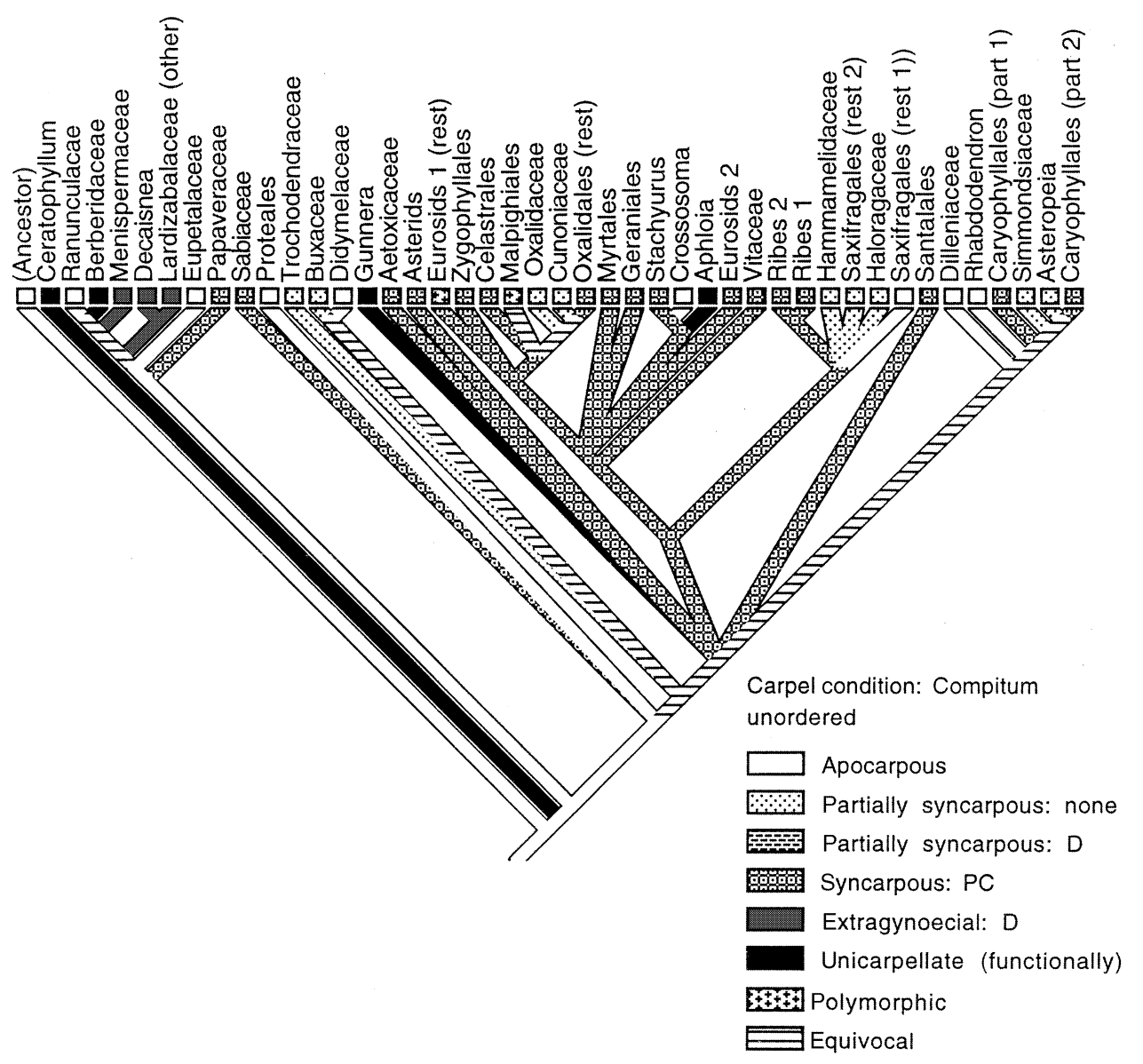

Fig. 2 Estimated phylogeny of 'eudicots', in part, from Soltis et al. $(1999,2000)$, depicting origins of different forms of syncarpy. Only taxa with informative phylogenetic positions and for which data could be obtained are shown. Abbreviations: D, compitum allowing distributed pollen tubes (syncarpy or extragynoecial compita allowing pollen to fertilize ovules in different carpels); PC, compitum allowing pollen competition (syncarpy or extragynoecial compita allowing pollen competition to occur in addition to fertilization of ovules in different carpels). 'None' refers to absence of compitum. 'Functionally unicarpellate' refers to flowers that are unicarpellate or are pseudomonomerous, regardless of whether they are of apocarpous or syncarpous origin.

(stigma or tip of style, without basal compita). These evolutionary transitions potentially increased the even distribution of pollen tubes to ovules, and hence seed set. They would have been generally less effective in enhancing pollen competition, however, because the destination of each pollen tube has been determined before much competition has occurred. (Consider the Apocynaceae/Ascepiadaceae, in which, at the stigma, each pollen tube is 'distributed' to one of five carpels, before any expression of tube growth rate is possible; see Endress et al., 1983.) In contrast, 11-18 origins involved total carpel fusion, or partial fusion with an ovarial compitum. These transitions potentially increased pollen competition as well as even distribution of pollen tubes, and hence potentially enhanced offspring quality as well as quantity (see below). In the evolution of extragynoecial compita, three to four origins increased even distribution of pollen tubes, and two increased pollen competition plus even distribution of tubes (Figs 1 and 2).

\section{Analytical results}

The first set of results is from the analytical computations for all combinations of 1-97 pollen grains, 1-10 ovules per carpel (stigma), and thresholds of one, two, five and ten pollen grains. Five carpels per flower were used in these analyses. Pollen fitness values were drawn from a normal distribution with a mean of 100, standard deviation of $10(\mathrm{CV}=0.1)$.

Increasing amounts of pollen arriving on stigmas of five-carpeled flowers led to higher seed production asymptotically for both flowers with unfused carpels and those with fused (functionally compital) carpels. The main difference between apocarpous and syncarpous flowers was that the latter reached their seed-production 


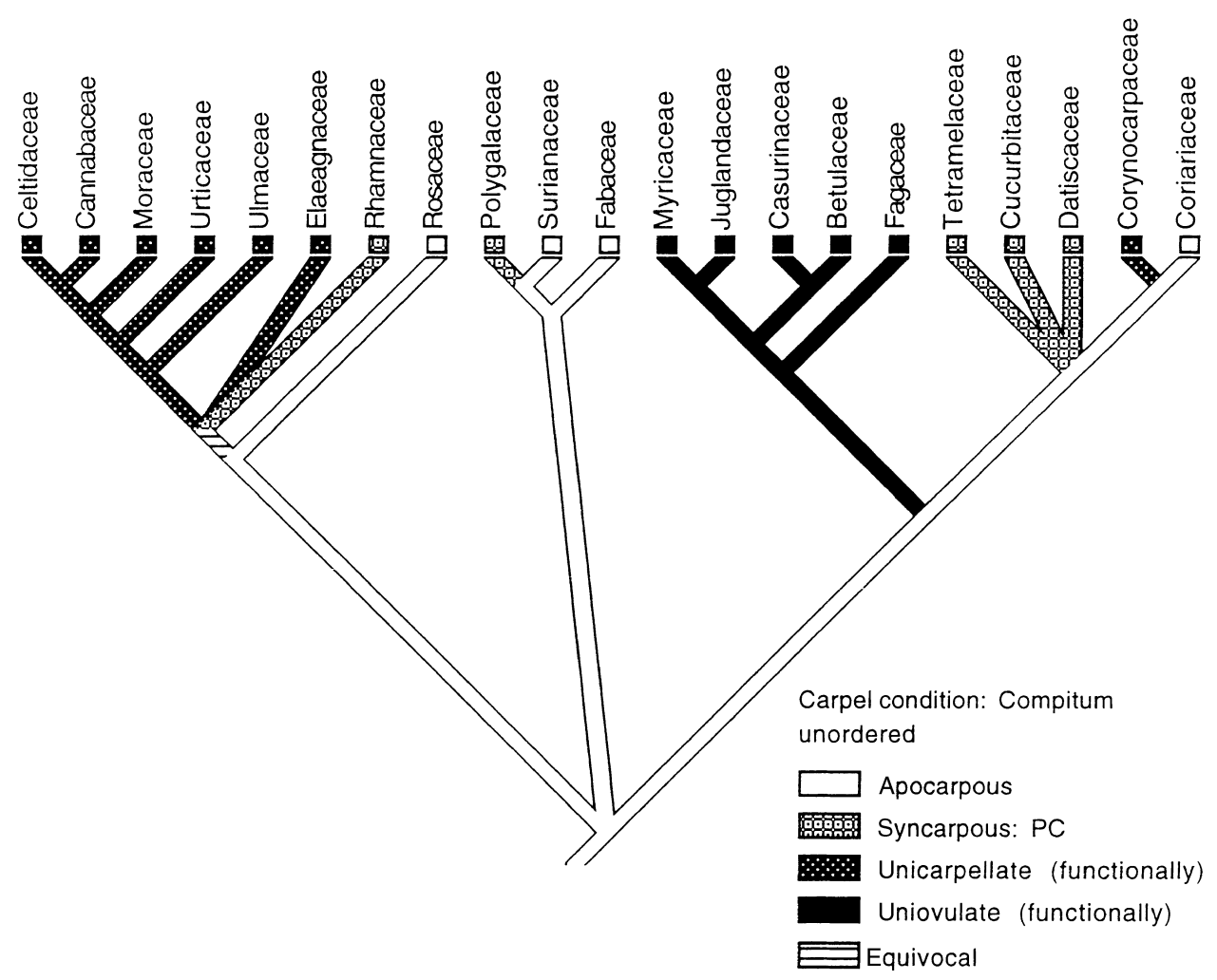

Fig. 3 Estimated phylogeny of 'eurosids', in part, from Soltis et al. $(1999,2000)$, depicting origins of different forms of syncarpy. Only taxa with informative phylogenetic positions and for which data could be obtained are shown. Abbreviations: D, compitum allowing distributed pollen tubes (syncarpy or extragynoecial compita allowing pollen to fertilize ovules in different carpels); PC, compitum allowing pollen competition (syncarpy or extragynoecial compita allowing pollen competition to occur in addition to fertilization of ovules in different carpels). 'None' refers to absence of compitum. 'Functionally unicarpellate' refers to flowers that are unicarpellate or are pseudomonomerous, regardless of whether they are of apocarpous or syncarpous origin. 'Functionally uni-ovulate' refers to the condition of having only one function ovule per flower by loss of ovules and/or carpels, regardless of whether it is of apocarpous or syncarpous origin.

asymptote earlier (Fig. 4). Increasing the number of ovules per carpel from one to ten shifted the asymptote of the curve to the right (higher pollen numbers) and increased the difference between the fitness-gain trajectories (with increasing pollen arrival) of apocarpous and syncarpous flowers. At higher ovule numbers apocarpous seed set rose with increasing pollen number more slowly than syncarpous flowers (Fig. 4). Increasing the pollengermination threshold from one to ten pollen grains also shifted the asymptotes to the right and increased the difference between the trajectories of apocarpous and syncarpous flowers (Fig. 4). Thus the advantage of syncarpy over apocarpy, in terms of numbers of seeds produced, increases with higher numbers of ovules per carpel and with higher thresholds for germination.

Figure 5 shows the effect of varying the same parameters on average offspring and maternal fitness (via paternal pollen fitness) under the assumption that paternal pollen fitness is correlated directly with pollentube growth rates and affects offspring quality (Snow $\delta$ Spira, 1996; Marshall, 1998). For both apocarpous and syncarpous flowers the average offspring quality $(\boldsymbol{P F})$ increased with pollen number, as is expected from pollen-competition theory. However, the average offspring quality generally increased more rapidly and stayed higher (at least up to 100 pollen grains) in syncarpous flowers. An exception to syncarpy outperforming apocarpy was seen, however, where the number of pollen grains was less than the number of ovules (Fig. 5). Here average offspring fitness was higher on apocarpous flowers because pollen competition is actually greater on carpels that by chance receive more pollen than it has ovules (at the expense of other carpels that received too little pollen for full seed set). This inversion of fitness is not biologically meaningful, however, because this is the region in which seed set by apocarpous flowers is much lower than in syncarpous flowers (Fig. 4), and a slight increase in mean offspring fitness is unlikely to make up for a substantial drop in offspring number (see below).

Increasing the number of ovules per carpel (per stigma) reduced the intensity of competition and the average offspring quality (PF; Fig. 5). This is because the ratio of pollen grains to ovules (an index of competition 

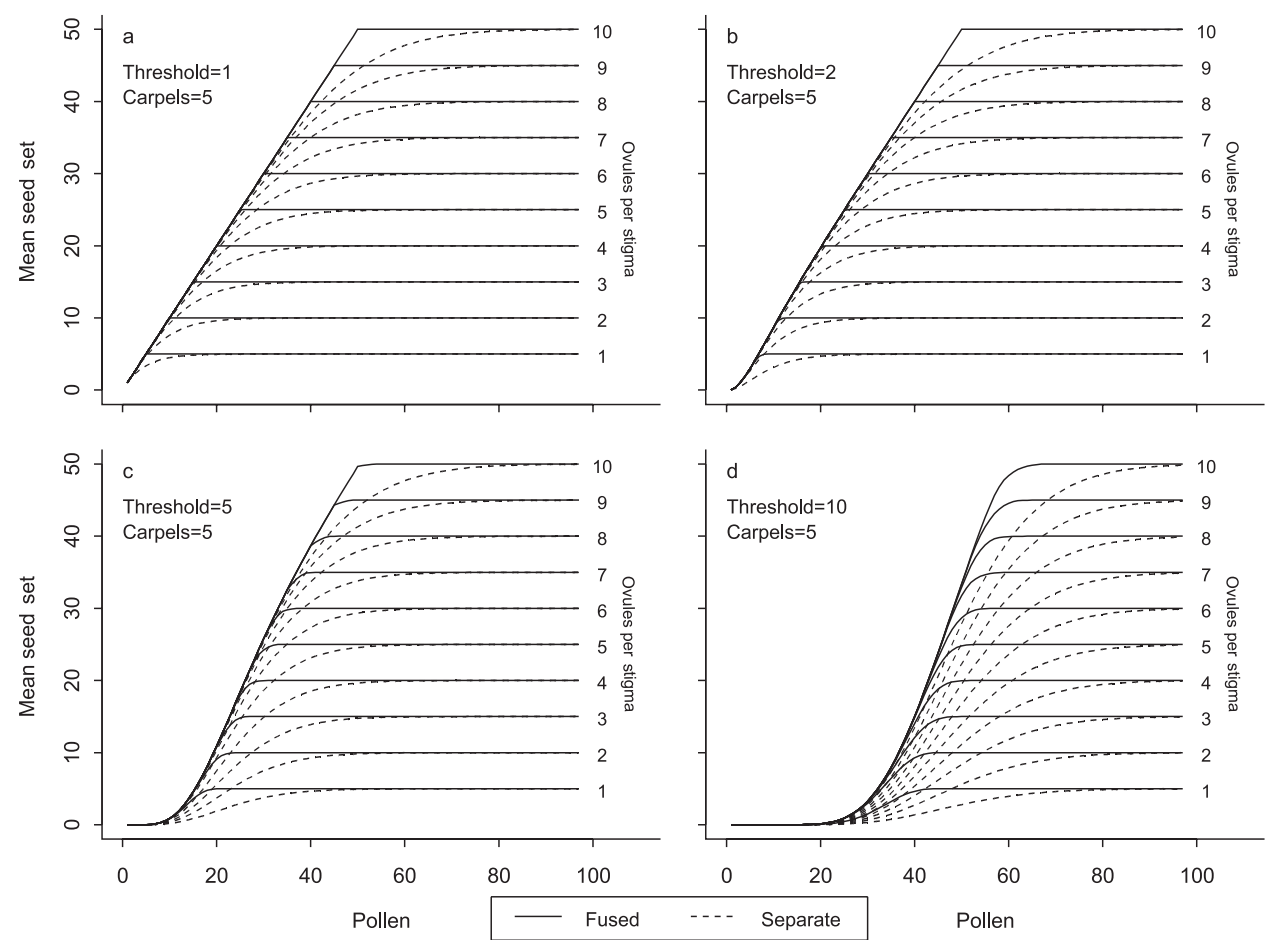

Fig. 4 Effects of variation in pollen load, carpel number, number of ovules per carpel and level of pollen-germination threshold on average seed set for flowers with syncarpous (solid line) vs. apocarpous (dotted line) pistils.
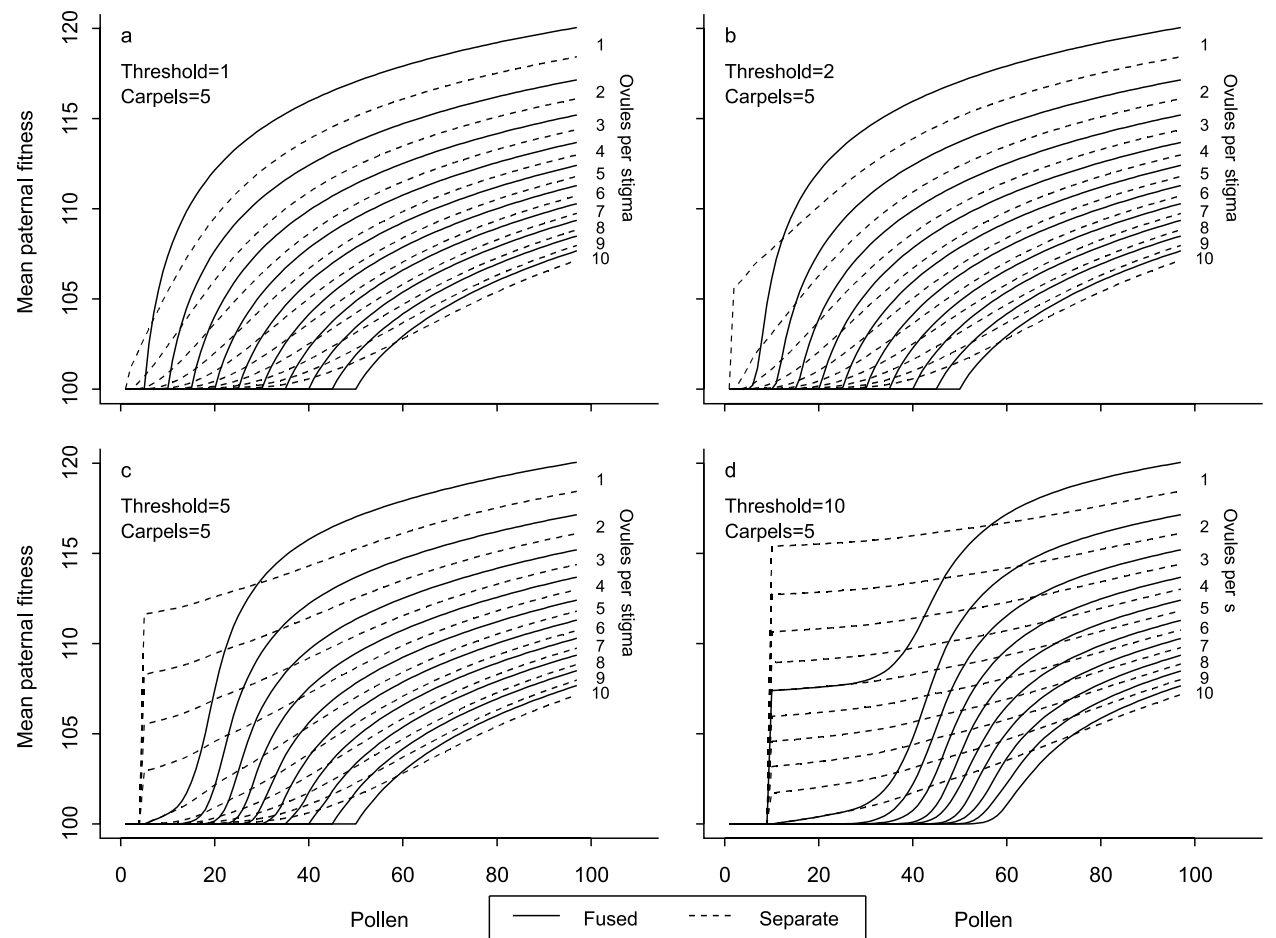

Fig. 5 Effects of variation in pollen load, carpel number, number of ovules per carpel and level of pollen-germination threshold on mean fitness of pollen grain fertilizing ovules in flowers with syncarpous (solid line) vs. apocarpous (dotted line) pistils. 
intensity) drops with increasing ovule number. The region of apparent apocarpous advantage increased, because pollen number remains below ovule number over a larger pollen-number space at higher ovule numbers (Fig. 5). This was more than compensated for by the greater reduction of seed set of apocarpous flowers relative to syncarpous flowers at high ovule numbers (Fig. 4).

Increasing the value of the pollen-germination threshold from one to ten shifted the syncarpous flower curves to the right (towards higher pollen numbers) and the apocarpous flower curves to the left (Fig. 5). This increased the apparent apocarpous advantage and expanded it over a larger range of pollen numbers. The apocarpous advantage is, however, again an artefact of the reduced seed production of apocarpous flowers under these conditions (cf. Fig. 4).

In order to account for the effect of syncarpy vs. apocarpy on offspring quality and quantity simultaneously, we used a fitness index incorporating both offspring quantity and quality. Values of this index greater than 1 indicate an advantage of syncarpy over apocarpy, 1 indicates equal fitness, and values less than 1 indicate that apocarpy results in higher fitness than syncarpy. Figure 6 shows the variation in this composite fitness index in response to variation in the same parameters displayed in Figs 4 and 5 and discussed above. Apocarpy never showed a composite fitness greater than syncarpy, and the advantage of syncarpy over apocarpy increased quickly with increasing pollen number until the number of pollen grains equalled the number ovules in the flower (Fig. 6). Thereafter the advantage declined with increasing pollen number. Increasing ovule number decreased the magnitude of the fitness difference (height of the peak) and shifted the peak to the right (towards higher pollen numbers).

Increasing the pollen-germination threshold from one to ten grains acted primarily to increase dramatically the magnitude of the fitness difference between syncarpy and apocarpy (increase peak height) especially at low ovule numbers. Another effect was to expand the breadth of the peak so that it became a broad plateau at germination thresholds of five and ten grains, especially at low numbers of ovules per carpel (Fig. 6).

The overall pattern that emerges from this series of analyses is that syncarpy is most strongly favoured over apocarpy when the amount of pollen arriving is about that minimally needed to generate full seed set. The advantage is greatly magnified and persists over a wider range of pollen numbers when there is a strong threshold effect on pollen germination. The advantages of syncarpy, in terms of offspring quantity and quality, diminish as pollen number increases, fading to near zero at very large numbers of pollen arriving on the stigmas.
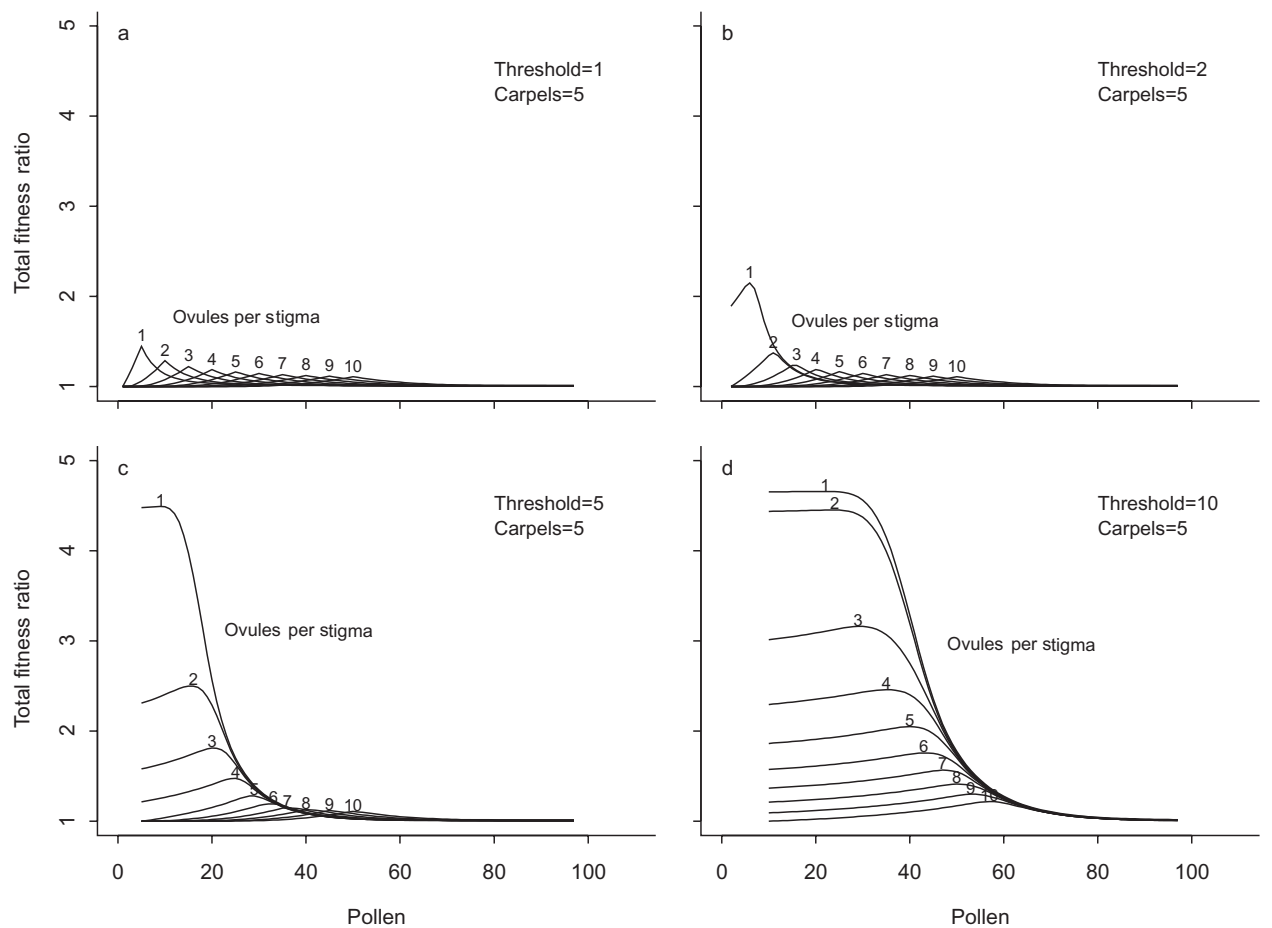

Fig. 6 Effects of variation in pollen load, carpel number, number of ovules per carpel and level of pollen-germination threshold on increment of total fitness score (product of relative quantity and quality of offspring) of syncarpous pistils over apocarpous pistils. A positive value indicates that syncarpy results in higher fitness than apocarpy and zero indicates no difference. 
In another set of analyses, computations were performed for several levels of variation in pollen fitness. Coefficients of variation were increased to $0.25(\mu=100$, $\sigma=25)$ and $0.5(\mu=100, \sigma=50)$. In these runs pollen grains were varied from 1 to 50 , with five carpels per flower, one ovule per carpel and no threshold. Figure 7 shows that increased variation in pollen fitness led to significant syncarpous advantage (reflected in the synthetic fitness index, lower right panel) occurring over broader range of pollen numbers. The change in shape of the fitness curve is the result of an effect on offspring quality, not quantity (Fig. 7).

\section{Simulation results}

We used simulations to extend the analyses of the possible advantages of syncarpy to higher numbers of ovules per carpel (150) and higher carpel numbers (10)
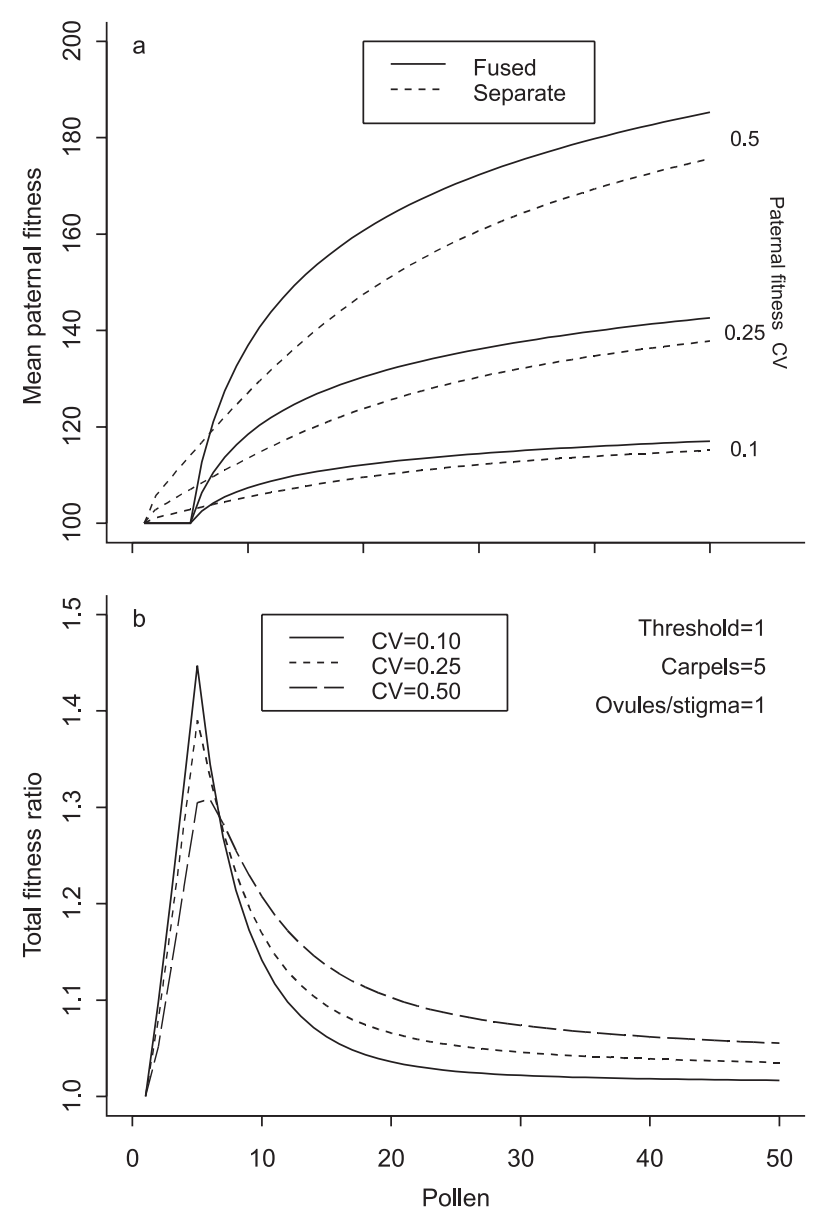

Fig. 7 Effects of variation in pollen load and coefficient of variation in paternal pollen fitness on average paternal-pollen component of offspring fitness for flowers with fused vs. separate carpels (A) and relative total fitness advantage (ratio) of syncarpy over apocarpy (B). than was explored analytically. Simulations were run for all combinations of 5 and 10 carpels per flower; 1-20, 25, $30,35,40,50,60,70,80,90,100,125$ and 150 pollen grains; 1, 10 and 100 ovules per carpel; and germination thresholds of 1, 2, 5 and 10 pollen grains.

The simulation results were largely consistent with the analytical results in terms of seed set. One exception was observed with 100 ovules per carpel: there was no difference between syncarpy and apocarpy in seed production when pollen number varied between 1 and 150 (Fig. 8). However, because the seed-set advantage of syncarpy (more even distribution of pollen tubes) reached its maximum when the number of pollen grains equalled the number of ovules (see ovules $=10$ function in Fig. 8), we expect the syncarpy advantage to kick in when the pollen number gets closer to 500 (not analysed). Raising carpel number from five to ten increased the advantage of syncarpy over apocarpy in seed production for both 5 and 100 ovules per carpel. It also caused the advantage to persist to higher pollen numbers (Fig. 8).

The simulation results of the effects of syncarpy on paternally contributed components of offspring quality were largely similar to the analytical results. However, again there was no fitness difference between syncarpy and apocarpy when there were 100 ovules per carpel and pollen number varied between 1 and 150 (Fig. 9). However, because the benefits of pollen competition begin to accrue when pollen-to-ovule ratios are greater than one (e.g. see ovules $=10$ curve in Fig. 9), it seems safe to infer that differences in fitness would have accrued at 500 pollen grains and higher (not analysed). The main effect of increasing carpel number from five to ten was to shift the crossover point (where offspring fitness of syncarpy first exceeds that of apocarpy) to higher pollen numbers (Fig. 9). The offspring-fitness advantage of syncarpy over apocarpy also presumably persists to higher pollen numbers, although these simulations did not include high enough pollen numbers to show this. As expected from the above results there was no difference in combined offspring fitness between syncarpy and apocarpy when there were 100 ovules per carpel and pollen number varied between 1 and 150 (Fig. 10), but as explained above, differences presumably accrued at higher pollen numbers. The main effect on the fitness index of increasing carpel number from five to ten was to shift the peak of the syncarpy advantage to higher pollen numbers (Fig. 10).

\section{Discussion}

\section{Phylogenetic analyses}

The phylogenetic analysis of trait evolution based on the three-locus tree (Soltis et al., 1999, 2000) supported earlier arguments that syncarpy has arisen repeatedly in the angiosperms. The present estimate is between 17 and 

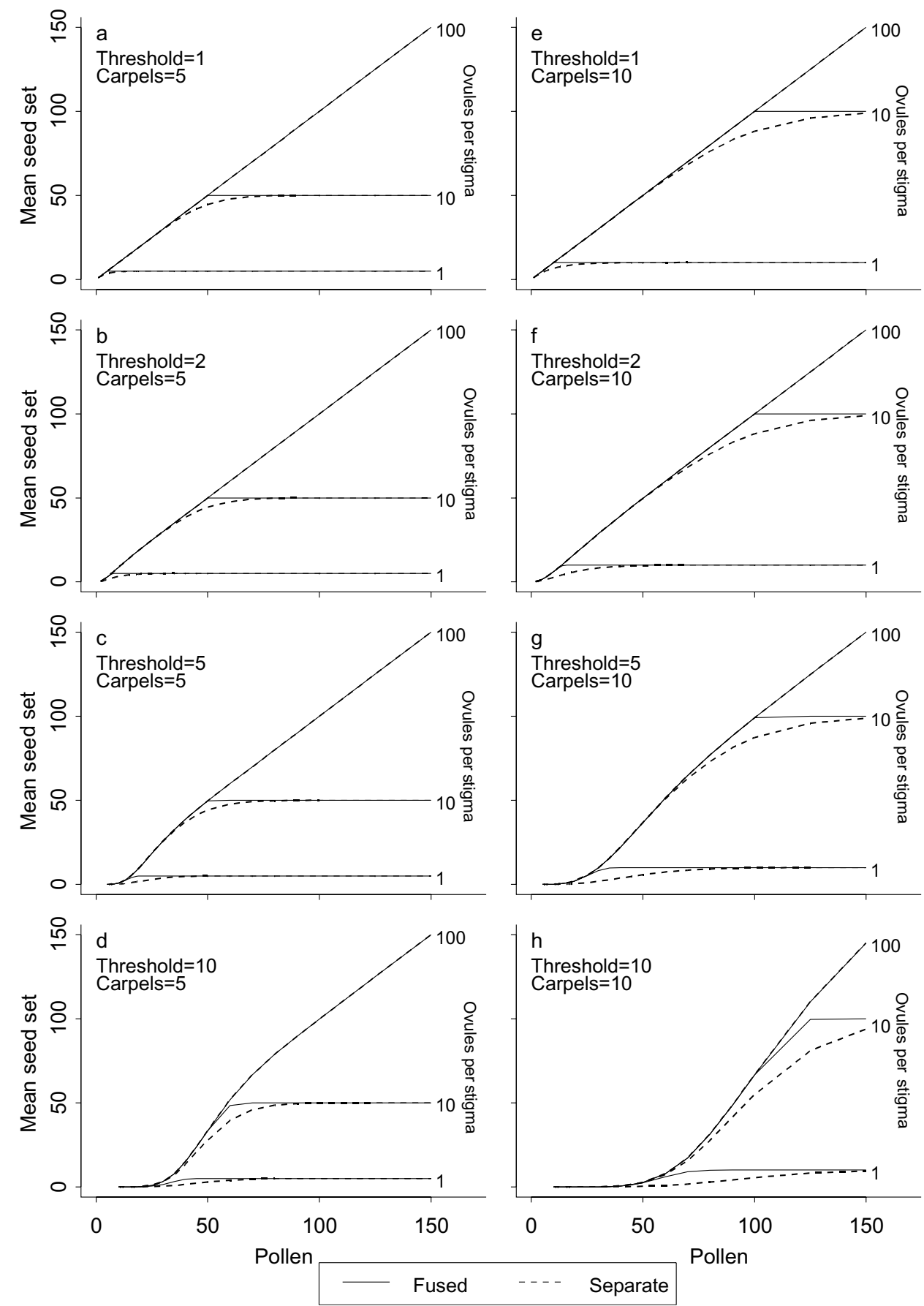

Fig. 8 Effects of variation in pollen load, number of ovules per carpel and level of pollen-germination threshold on average seed set for flowers with syncarpous (solid line) vs. apocarpous (dotted line) pistils. These functions were obtained over a larger range of values than in Fig. 4 using simulation, with carpels set at $5(\mathrm{~A}-\mathrm{D})$ and $10(\mathrm{E}-\mathrm{H})$.

26 independent origins of some form of syncarpy. This suggests that syncarpy is a key innovation (Endress, 2001) and has a broad adaptive advantage over apocarpy. Only two reversals to apocarpy were reconstructed unambiguously, although at least one other partial reversal has occurred in the Apocynaceae (Asterid lineage; not shown), and although they have post-genital stigma fusion and a functional compitum (Endress et al., 

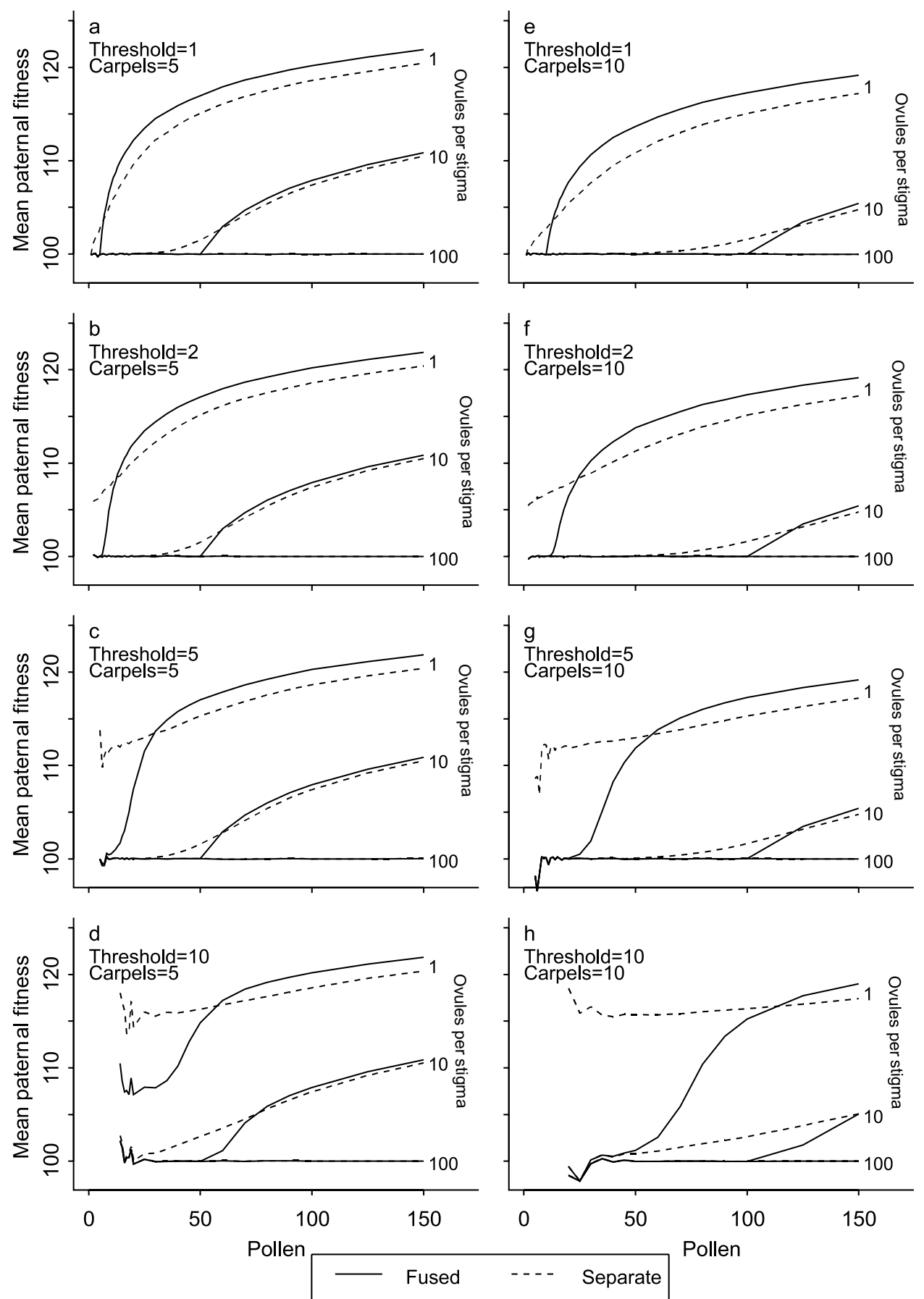

Fig. 9 Effects of variation in pollen load, number of ovules per carpel and level of pollen-germination threshold on average paternal pollen fitness for flowers with syncarpous (solid line) vs. apocarpous (dotted line) pistils. These functions were obtained over a larger range of values than in Fig. 5 using simulation, with carpels set at $5(\mathrm{~A}-\mathrm{D})$ and $10(\mathrm{E}-\mathrm{H})$.

1983). The paucity of reversals suggests that conditions favouring apocarpy over syncarpy are uncommon, as was indicated by our analytical results. Where it has occurred, it may reflect some advantage of apocarpy, such as extending the period during which ovules are fertilized and hence sampling a wider variety of sporophytic fathers, thereby increasing offspring genetic variation and/or reducing sib competition. 

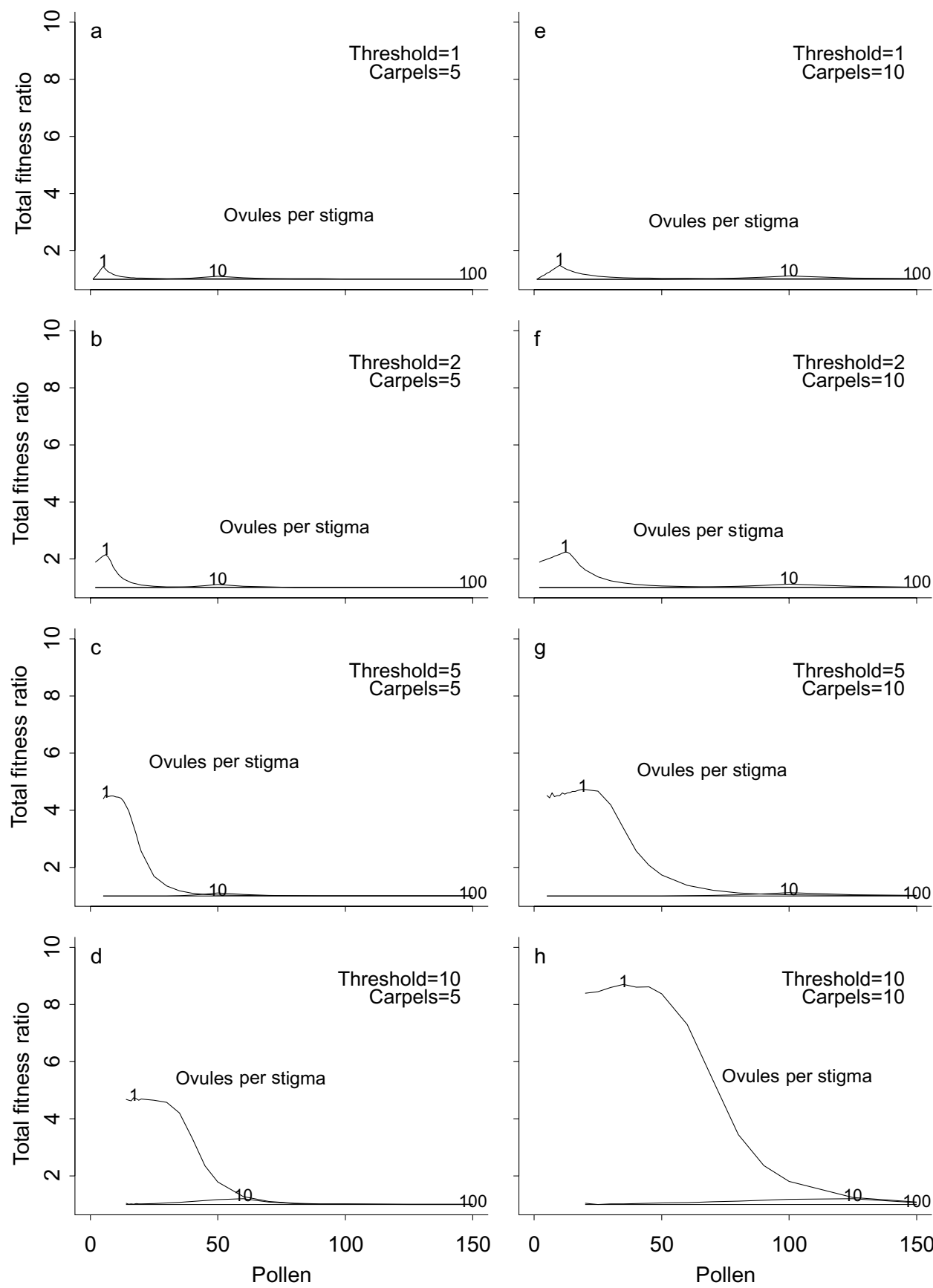

Fig. 10 Effects of variation in pollen load, number of ovules per carpel, and level of pollen-germination threshold on increment of average fitness score (product of relative quantity and quality of offspring) of syncarpous pistils over apocarpous pistils. A positive value indicates that syncarpy results in higher fitness than apocarpy and zero indicates no difference. These functions were obtained over a larger range of values than in Fig. 6 using simulation, with carpels set at $5(\mathrm{~A}-\mathrm{D})$ and $10(\mathrm{E}-\mathrm{H})$

One would predict that, if the origin of syncarpy were largely driven by selection for protection of ovaries and developing seeds or by enhancement of seed dispersal, then simple ovary fusion (without compita) would have evolved as at least as commonly as the kinds of carpel fusion that allow pollen tubes to cross between carpels. However, $76-77 \%$ of the $17-26$ estimated carpel-fusion events were of the type that facilitated pollen-tube crossing between carpels, supporting the offspring-quantity/quality hypothesis. This proportion is undoubtedly 
an underestimate, however, because of undetected or unreported compita in multilocular taxa. Our reconstruction also showed a minimum of five to six origins of extragynoecial compita (functional syncarpy with respect to our hypothesis), which allow pollen tubes to cross between carpels even in the absence of true syncarpy. This lends additional support to the offspring quantity/ quality hypothesis.

Whereas basal carpel fusion with a compitum promotes both even distribution of pollen tubes to ovules and enhances pollen competition, fusion of the stigmas or apical portion of the style promotes only the former. Thus if selection for offspring quantity (even distribution of pollen-tubes) were more important than selection for offspring quality (pollen-tube competition), one might predict apical carpel fusion to be as common as basal carpel fusion. However, only $10-15 \%$ of the $13-20$ carpel-fusion events forming compita involved the apical region. Thus the phylogenetic data tend to support the idea that selection for enhanced offspring quality is more important than selection for increased offspring quantity in driving the evolution of syncarpy. The balance between these two advantages likely lies in the pollination ecology: pollen limitation promotes the offspring quantity advantage, and ample pollen promotes the offspring quality advantage (see below). Perhaps overall, pollen limitation has been less frequent than resource limitation (but see Burd, 1994).

\section{Analytical and simulation studies}

The analytical and simulation studies of syncarpous and apocarpous flowers also supported the potential importance of syncarpy in increasing quantity and/or quality of offspring under a variety of conditions. These analyses showed complex responses of the syncarpy advantage to variation in pollen load, number of carpels, ovule number, threshold number for pollen germination, and coefficients of variation of pollen fitness. Under almost all conditions, however, syncarpous flowers had higher fitness than apocarpous flowers, although the advantage declined gradually with increasing amounts of arriving pollen. Syncarpy is most strongly favoured over apocarpy when the amount of pollen arriving is about that minimally needed to generate full seed set. The advantage is greatly magnified and persists over a wider range of pollen numbers when there is a strong threshold effect on pollen germination and when there is high variance in paternal genetic quality.

At pollen numbers less than $c$. 1.5-2 times the number of ovules, the advantage of syncarpous flowers accrued from producing more seeds. At higher pollen numbers the advantage of syncarpy accrued from more intense pollen competition increasing average fitness of the seeds (assuming genetically superior pollen have faster pollen tubes). The magnitude of the increase in maternal fitness with syncarpy increased with the size of the threshold effect, and this fitness difference was effected mostly through differences in the quantity of offspring produced. The magnitude of the increase in maternal fitness with syncarpy also increased with decreasing number of ovules per carpel, and with increasing variance in pollen quality. Both these fitness differences were effected primarily through increases in quality of offspring. In general, all these effects (threshold, carpel number, pollen variance) were interactive in the statistical sense.

To return to our original questions, it is obvious that variation in pollen number and pollen-arrival schedules has a major influence on the advantages of syncarpy over apocarpy. The abundance and timing of arriving pollen can minimize or accentuate fitness differences. Thus the evolution of syncarpy has probably been system dependent, with variation in pollination ecology, population genetics, and pre-existing morphology playing important roles in promoting or inhibiting the shift from apocarpy to syncarpy in different lineages. For example, populations with high variance in genetic quality of pollen or with few ovules per carpel would be expected to evolve completely fused carpels or ovarian compita, at least in the absence of genetic constraints. Similarly, lineages experiencing frequent pollen limitation or marginally adequate pollination (Bierzychudek, 1981; Burd, 1994) could be expected to evolve fused stigmas, extragynoecial compita, or any form of compital syncarpy that promotes even distribution of pollen tubes among carpels. In contrast, lineages that usually experience copious pollination in large pulses (Bierzychudek, 1981) and low variance in genetic quality of pollen might be expected to retain (or revert to) apocarpy.

The relative importance of seed quantity vs. seed quality as mechanisms in the evolution of syncarpy varies with pollination ecology and selection on other phases of the life cycle. Under frequent pollen limitation, offspring quantity is more important. When pollen arriving is generally enough to fertilize all ovules but less than approximately 20-80 times the number of ovules, offspring quality is more important. When selection on plant life history favours fecundity (number of seeds produced), selection for syncarpy would be strong (via fecundity effect) as long as the amount of arriving pollen is regularly less than about two times the number of ovules. However, when selection for fit offspring predominates, selection for the offspring-quality effect of syncarpy would be strong and remain so over a broad range of arriving-pollen amounts.

Arrival of pollen on stigmas in a random distribution is clearly more realistic than the even distribution used in the simplified heuristic model presented by Endress (1982). However, the effect of greater realism was only to increase the fitness advantage of syncarpy postulated by Endress, particularly through the increase in offspring quantity under low pollen numbers. 
The advantages of syncarpy do indeed vary greatly and interactively with variation in ovule number, carpel number, pollen number and pollen-germination threshold. When using realistic variation in these parameters, the behaviour of the system is extremely complex and impossible to predict from analysis of single factors. Nevertheless, it seems clear that advantages of syncarpy often accrue from increases in both offspring number and quality, and these advantages likely explain the multiple origins and prevalence of syncarpy in modern angiosperms.

\section{Acknowledgments}

We thank Peter Endress and two anonymous reviewers for comments on an earlier version of the manuscript and the US National Science Foundation for support (grants nos. DEB-9318640 and DEB-9708333 to WSA).

\section{References}

Aptech Systems. 1993. GAUSS. Aptech Systems, Maple Valley, WA, USA.

Armbruster, W.S., Martin, P., Kidd, J., Stafford, R. \& Rogers, D.G. 1995. Reproductive significance of indirect pollen-tube growth in Dalechampia (Euphorbiaceae). Am. J. Bot. 82: 51-56.

Armbruster, W.S., Di Stilio, V.S., Tuxill, J.D., Flores, T.C. 8 Velasquez Runk, J.L. 1999. Covariance and decoupling of floral and vegetative traits in nine neotropical plants: a re-evaluation of Berg's correlation-pleiades concept. Am. J. Bot. 86: 39-55.

Bierzychudek, P. 1981. Pollinator limitation of plant reproductive effort. Am. Nat. 117: 838-840.

Burd, M. 1994. Bateman's principle and plant reproduction: the role of pollen limitation in fruit and seed set. Bot. Rev. 60: 83139.

Carr, S.G.M. \& Carr, D.J. 1961. The functional significance of syncarpy. Phytomophologiy 11: 249-256.

Chase, M.W. et al. 1993. Phylogenetics of seed plants - an analysis of nucleotide-sequences from the plastid gene rbcl. Ann. Missouri Bot. Garden 80: 528-580.

Cronquist, A. 1981. An Integrated System of Classification of Flowering Plants. Columbia University Press, New York, USA

Donoghue, M.J. \& Ackerly, D.D. 1996. Phylogenetic uncertainties and sensitivity analyses in comparative biology. Philos. Trans. R. Soc. Lond. B. Biol. Sci. 351: 1241-1249.

Endress, P.K. 1982. Syncarpy and alternative modes of escaping disadvantages of apocarpy in primitive angiosperms. Taxon $\mathbf{3 1}$ : 48-52.

Endress, P.K. 1995. Floral structure and evolution in Ranunculaceae. Plant Syst. Evol. 206: 47-61.

Endress, P.K. 2001. Origins of flower morphology. J. Exp Zool. (Mol Dev Evol) 291: 105-115.

Endress, P.K. \& Igersheim, A. 2000. Gynoecium structure and evolution in basal angiosperms. Int. J. Plants Sci. 161: S211S223.

Endress, P.K., Jenny, M. \& Fallen, M.E. 1983. Convergent elaboration of apocarpous gynoecia in higher advanced dicotyledons (Sapindales, Malvales, Gentianales). Nordic J. Bot. 3: 293-300.
Falque, M., Vincent, A., Vaissiere, B.E. \& Eskes, A.B. 1995. Effect of pollination intensity on fruit and seed set in cacao (Theobroma cacao L.). Sexual Plant Reprod. 8: 354-360.

Igersheim, A. \& Endress, P.K. 1997. Gynoecium diversity and systematics of the Magnoliaceae and winteroids. Bot. J. Linn. Soc. 124: 213-271.

Maddison, W.P. \& Maddison, D.R. 1992. Macclade. Version 3. Sinauer, Sunderland, MA, USA

Marshall, D.L. 1998. Pollen donor performance can be consistent across maternal plants in wild radish (Raphanus sativus, Brassicaceae): a necessary condition for the action of sexual selection. Am. J. Bot. 85: 1389-1397.

Mathsoft Inc. 1994. S-plus, Version 3.3 for Windows. Mathsoft Inc., Seattle, WA, USA

McKenna, M.A. 1985. Heterostyly and microgametophytic selection: the effect of pollen competition on sporophyte vigor in two distylous species. In: Biotechnology and Ecology of Pollen (D. L. Mulcahy, G. B. Mulcahy \& E. Ottaviano, eds), pp. 443-448. Springer-Verlag, Berlin.

McKenna, M.A. \& Mulcahy, D.L. 1983. Ecological aspects of gametophytic competition in Dianthus chinensis. In: Pollen: Biology and Implications for Plant Breeding (D. L. Mulcahy \& E. Ottaviano, eds), pp. 419-424. Elsevier, New York, USA

Mitchell, R.J. 1997. Effects of pollination intensity on Lesquerella fendleri seed set: variation among plants. Oecologia 109: 382388.

Mulcahy, D.L. 1979. The rise of the angiosperms, a genecological factor. Science 206: 20-23.

Mulcahy, D.L. 1983. Models of pollen tube competition in Geranium maculatum. In: Pollination Biology (L. Real., ed.), pp. 151-161. Academic Press, New York, USA

Mulcahy, D.L. \& Mulcahy, G.B. 1975. The influence of gametophytic competition on sporophytic quality in Dianthus chinensis. Theor. Appl. Genet. 46: 277-280.

Mulcahy, D.L. \& Mulcahy, G.B. 1987. The effects of pollen competition. Am. Sci. 75: 44-50.

Mulcahy, D.L., Curtis, P.S. \& Snow, A.A. 1983. Pollen Competition in a Natural Population. Handbook of Experimental Pollination Ecology, pp. 330-337. Van Nostrand Reinhold, New York, USA.

Ottaviano, E., Sari-Gorla, M. \& Mulcahy, D.L. 1980. Pollen tube growth rates in Zea mays: implications for genetic improvement of crops. Science 210: 437-438.

Renner, S.S., Schwarzbach, A.E. \& Lohmann, L. 1997. Phylogenetic position and floral function of Siparuna (Siparunaceae: Laurales). Int. J. Plant Sci. 158: S89-S98.

van der Schoot, C., Dietrich, M.A., Storms, M., Verbeke, J.A. \& Lucas, W.J. 1995. Establishment of a cell-to-cell communication pathway between separate carpels during gynoecium development. Planta 195: 450-455.

Silvertown, J., Franco, M. \& Harper, J.L. 1997. Plant Life Histories: Ecology, Phylogeny, and Evolution. Cambridge University Press, Cambridge, UK.

Snow, A.A. 1982. Pollination intensity and potential seed set in Passiflora vitifolia. Oecologia 55: 231-237.

Snow, A.A. \& Spira, T.P. 1996. Pollen-tube competition and male fitness in Hibiscus moscheutos. Evolution 50: 1866-1870.

Soltis, P.S., Soltis, D.E. \& Chase, M.W. 1999. Angiosperm phylogeny inferred from multiple genes as a tool for comparative biology. Nature 402: 402-404.

Soltis, P.S., Soltis, D.E., Zanis, M.J. \& Kim, S. 2000. Basal lineages of angiosperms: relationships and implications for floral evolution. Int. J. Plant Sci. 161: S97-S107. 
Stebbins, G.L. 1974. Flowering Plants: Evolution Above the Species Level. Harvard University Press, Cambridge, MA, USA

Svoma, E. 1998. Studies on the embryology and gynoecium structures in Drimys winteri (Winteraceae) and some Annonaceae. Plant Syst. Evol. 209: 205-229.

Walker, D.B. 1978. Postgenital carpel fusion in Catharanthus roseus (Apocynaceae) IV. Significance of the fusion. Am. J. Bot. 65: 119-121.

Williams, E.G., Sage, T.L. \& Thien, L.B. 1993. Functional syncarpy by intercarpellary growth of pollen tubes in a primitive apocarpous angiosperm, Illicium floridanum (Illiciaceae). Am. J. Bot. 80: 137-142.

Willson, M.F. 1991. Sexual selection, sexual dimorphism and plant phylogeny. Evol. Ecol. 5: 69-87.

Windsor, J.A., Davis, L.E. \& Stephenson, A.G. 1987. The relationship between pollen load and fruit maturation and the effect of pollen load on offspring vigor in Cucurbita pepo. Am. Nat. 129: 643-656.

Received: 23 October 2001; revised 22 December 2001; accepted 13 February 2002

\section{Appendix 1}

\section{Analytical approach}

For given numbers of carpels per flower $(\boldsymbol{n})$, ovules per carpel $(\boldsymbol{o})$, pollen grains $(\boldsymbol{m})$, and pollen-germination threshold $(\boldsymbol{t})$, we can calculate the mean seed set and mean pollen-determined offspring fitness for syncarpous and apocarpous strategies. We first considered all possible ways of placing $\boldsymbol{m}$ pollen grains on $\boldsymbol{n}$ stigmas. We did this by first determining all unique unordered patterns that are possible. For example, consider the case of three stigmas and two pollen grains. There are two possible unordered patterns: (1) both pollen grains on a single stigma for a pattern of 2-0-0, or (2) 1 pollen grain on each of two stigmas for a pattern of 1-1-0.

Once the possible patterns of pollen placement were determined, we calculated the number of ways each pattern can occur $\left(r_{i}\right)$ as

$$
r_{i}=\frac{n !}{\prod_{l=0}^{m} n_{i l} !}
$$

where $\boldsymbol{n}_{\mathrm{il}}$ is the number of carpels in the $\boldsymbol{i}^{\text {th }}$ pattern with $l$ pollen grains. Using the above example with $\boldsymbol{n}=3$ and $\boldsymbol{m}=2$, we get $\boldsymbol{n}_{10}=2, \boldsymbol{n}_{11}=0$, and $\boldsymbol{n}_{12}=1$ for pattern (1), and $\boldsymbol{n}_{20}=1, \boldsymbol{n}_{21}=2$, and $\boldsymbol{n}_{22}=0$ for pattern (2). Therefore, $\boldsymbol{r}_{1}=\boldsymbol{r}_{2}=3$. Note that this is still only considering patterns and does not distinguish between individual pollen grains. The probability of each pattern occurring $\left(\boldsymbol{p}_{\mathrm{i}}\right)$ was then calculated as

$$
p_{i}=r_{i} m ! \frac{\left(\frac{1}{n}\right)^{m}}{\prod_{j=1}^{n} x_{i j} !}
$$

where $\boldsymbol{x}_{\mathrm{ij}}$ is the number of pollen grains on the $j^{\text {th }}$ carpel in the $i^{\text {th }}$ pattern. Note that $\sum_{i} p_{i}=1$ and $\sum_{i} x_{i j}=m$ for all $i$. Continuing with the example, we find $x_{11}=2$, $x_{12}=0$, and $x_{13}=0$ for pattern (1), and $x_{21}=1, x_{22}=1$, and $x_{23}=0$ for pattern (2). Therefore, $p_{1}=1 / 3$ and $p_{2}=2 / 3$. These probabilities differ because we are now considering placement of individual pollen grains. There is only one way to place two pollen grains on a single stigma, while there are two ways of placing two pollen grains on two separate stigmas.

\section{Mean seed set}

Each stigma required a minimum number of pollen grains before any of its pollen were considered available to set seed. The number of grains available for fertilization on the $\boldsymbol{j}^{\text {th }}$ carpel in the $\boldsymbol{i}^{\text {th }}$ pattern was defined as

$$
x_{i j}^{*}=\mathbf{I}_{x_{i j} \geq t} \cdot x_{i j}
$$

where $\boldsymbol{t}$ is the pollen-germination threshold and the expression $\mathbf{I}_{x_{i j} \geq t}$ is an indicator function that equals 1 when $x_{\mathrm{ij}} \geq \boldsymbol{t}$ and 0 otherwise, effectively eliminating pollen on stigmas that received less than the threshold number of pollen grains. From this, we calculated the number of seeds set from the $\boldsymbol{j}^{\text {th }}$ carpel in the $\boldsymbol{i}^{\text {th }}$ pattern for an apocarpous flower as

$$
s_{i j}=\min \left(x_{i j}^{*}, o\right)
$$

where $\boldsymbol{o}$ is the number of ovules per carpel. If the threshold was reached, then the number of pollen grains that fertilized ovules cannot exceed $\boldsymbol{o}$, hence the minimum function. The mean seed set for an apocarpous flower $\left(\boldsymbol{S} \boldsymbol{S}_{\text {apo }}\right)$ was then calculated as

$$
S S_{\text {apo }}=\sum_{i=1}^{y} p_{i} \sum_{j=1}^{n} s_{i j}
$$

where $\boldsymbol{y}$ is the number of unique unordered pollen placement patterns.

The mean seed set for a syncarpous flower was determined by pooling all available pollen grains together. The number of seeds set in the $\boldsymbol{i}^{\text {th }}$ pattern was

$$
s_{i}=\min \left(\sum_{j=1}^{n} x_{i j}^{*}, o \cdot n\right)
$$

In this case, all pollen from stigmas that reached the pollen-germination threshold were summed, with the total number of pollen grains that fertilized ovules not exceeding $\boldsymbol{o}$ times $\boldsymbol{n}$, the total number of ovules per flower. The mean seed set for a syncarpous flower $\left(S S_{\text {syn }}\right)$ was calculated as

$$
S S_{s y n}=\sum_{i=1}^{y} p_{i} S_{i}
$$

\section{Mean pollen-determined offspring fitness}

Fitness of pollen grains was assumed to be normally distributed with a mean $\mu$ and standard deviation $\sigma$, where larger values represent higher genetic quality as 
reflected in greater pollen-tube growth rates. The mean offspring fitness was determined by competition among the pollen grains arriving on the stigma and 'attempting' to fertilize ovule. The mean pollen-determined offspring fitness for apocarpous flowers $\left(\boldsymbol{P} \boldsymbol{F}_{\text {apo }}\right)$ was calculated as

$$
P F_{a p o}=\mu+\sigma \sum_{i=1}^{y} p_{i}^{*} \sum_{j=1}^{n} \sum_{k=x^{*} i j-s_{i j}+1}^{x_{i j}^{*}} \mathbf{E}\left(z_{i j(k)}\right)
$$

where

$$
p_{i}^{*}=\frac{p_{i}}{\sum_{i=1}^{y} \mathbf{I}_{x_{i}^{*}>0} \cdot p_{i}}
$$

and

$$
\mathbf{E}\left(z_{i j(k)}\right)=\int_{-\infty}^{\infty} x f\left(x_{i j(k)}\right) d x
$$

In $(10), x_{i}^{*}=\sum_{j=1}^{n} x_{i j}^{*}$ so that the $\boldsymbol{p}_{\mathrm{i}}$ 's are summed only from patterns that set at least one seed. This provided the new probability of a pattern occurring, $p^{*}{ }_{i}$, that was conditional on at least one seed being set. In (11), $f\left(x_{i j(k)}\right)$ is the probability distribution function for the $\boldsymbol{k}^{\text {th }}$ order statistic for $x_{i j}{ }^{*}$ realizations from a standard normal distribution, given as

$$
f\left(x_{i j(k)}\right)=\frac{x_{i j}^{*} !}{(k-1) !\left(x_{i j}^{*}-k\right) !} f(x)[\mathbf{F}(x)]^{k-1}[1-\mathbf{F}(\mathbf{x})]^{x_{i j}^{*}-k}
$$

where $f(x)$ and $\boldsymbol{F}(\boldsymbol{x})$ are the pdf and cdf, respectively, for a standard normal distribution. Equation 11 was used to calculate the expected value of the $\boldsymbol{k}^{\text {th }}$ order statistic out of $x_{i j}{ }^{*}$. For example, if 2 pollen grains out of 5 on a stigma set seed, then (11) would be used to determined the expected value for the most fit and second most fit grains ( $\mathbf{k}=5$ and 4, respectively) out of a sample size of 5 . Patterns that did not set any seed were not considered in the overall average. Because calculations were performed for a standard normal distribution, the conversion to a normal distribution with a mean of $\mu$ and standard deviation of $\sigma$ was made in (9).

The mean offspring fitness for syncarpous flowers $\left(P F_{\text {syn }}\right)$ was calculated as

$$
P F_{\text {syn }}=\mu+\sigma \sum_{i=1}^{y} p_{i}^{*} \sum_{k=x^{*}{ }_{i}-s_{i}+1}^{x_{i}^{*}} \mathbf{E}\left(z_{i(k)}\right)
$$

where

$$
\mathbf{E}\left(z_{i(k)}\right)=\int_{-\infty}^{\infty} x f\left(x_{i(k)}\right) d x
$$

and

$$
f\left(x_{i(k)}\right)=\frac{x_{i}^{*} !}{(k-1) !\left(x_{i}^{*}-k\right) !} f(x)[\mathbf{F}(x)]^{k-1}[1-\mathbf{F}(\mathbf{x})]^{x_{i}^{*}-k}
$$

